\title{
Rice (Oryza sativa L.) bran preserves cardiac function by modulating pro-inflammatory cytokines and redox state in the myocardium from obese rats
}

\author{
Jéssica Leite Garcia ${ }^{1}$ - Danielle Fernandes Vileigas ${ }^{2}$ (D) . Cristina Schmitt Gregolin ${ }^{1}$ - Mariane Róvero Costa ${ }^{1}$.

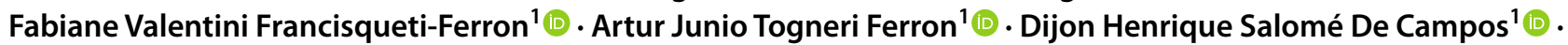

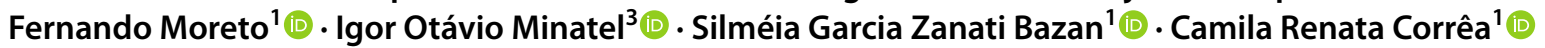

Received: 10 April 2021 / Accepted: 28 September 2021 / Published online: 12 October 2021

(c) The Author(s) 2021

\begin{abstract}
Purpose This study aimed to evaluate the effect of rice bran (RB) supplementation to a high-sugar fat (HSF) diet on cardiac dysfunction in an experimental obesity model.

Methods Male Wistar rats were distributed into three groups: control, high-sugar fat, and high-sugar fat supplemented with $11 \%$ RB for 20 weeks.

Results HSF diet promoted obesity and metabolic complications. Obese rats showed cardiac structural and functional impairment associated with high levels of interleukin-6, tumoral necrosis factor alpha, and malondialdehyde, and decreased activity of superoxide dismutase and catalase in the myocardium. RB supplementation was able to mitigate obesity and its metabolic alterations in HSF diet-fed animals. Moreover, the RB also prevented structural and functional damage, inflammation, and redox imbalance in the heart of these animals.

Conclusion This study suggests that RB supplementation prevents cardiac dysfunction in rats fed on HSF by modulating systemic metabolic complications and inflammation and oxidative stress in the myocardium, representing potential alternative therapy.
\end{abstract}

Keywords Rice bran · Western diet · Inflammation · Oxidative stress · Cardiac remodeling $\cdot$ Insulin resistance

\section{Introduction}

The contemporary dietary habits, especially the high consumption of processed foods rich in sugar and fat, associated with overnutrition and a sedentary lifestyle, have significantly increased the worldwide prevalence of obesity [ 1 , 2], a complex metabolic disease defined as an abnormal or excessive accumulation of adipose tissue within the body that may impair health [3].

Jéssica Leite Garcia

jessica.leite@unesp.br

1 São Paulo State University (UNESP), Medical School, Botucatu, Brazil

2 Department of Biochemistry, Institute of Chemistry, University of São Paulo (USP), São Paulo, Brazil

3 São Paulo State University (UNESP), Institute of Biosciences, Botucatu, Brazil
A consistent body of evidence shows that obesity promotes hemodynamics, neurohormonal and metabolic changes that may contribute to alterations in cardiac structure and ventricular function, progressing to heart failure depending on the duration and severity of obesity [4-6]. The pathophysiology of cardiac dysfunction due to excess adipose tissue is complex. In addition to metabolic complications such as dyslipidemia, insulin resistance, hyperglycemia, and hyperinsulinemia, the quality per ser of the diet can also cause an attack on the heart by different mechanisms $[1,6]$. Evidence suggests that the imbalance of the redox state, also known as oxidative stress, and the high release of pro-inflammatory cytokines are strongly involved in the etiology of obesity-related cardiomyopathy. Thus, to investigate therapeutic strategies is essential for the prevention and treatment of heart disease owing to obesity $[7,8]$.

The consumption of plant foods, rich in an array of bioactive compounds, has emerged as an alternative to ameliorate the harmful effects of obesity and its related disorders [9, 
10]. Rice (Oryza sativa L.) is the second most-consumed grain in the world, after wheat, and constitutes the dietary stable of half of the world population [11, 12]. Rice is preferably consumed in the polished form (white rice); however, the bran layer removed from the rice contains the major bioactive compounds [13]. Rice bran (RB) is a byproduct of the rice milling industry, obtained after rice kernel polishing. It is noteworthy that, every year, around $90 \%$ of RB is used as animal feed or discarded [11]. RB constitutes about $10 \%$ of the total weight of rough rice and contains hundreds of different bioactive components, mainly tocopherols, tocotrienols, and oryzanols, and in less concentration, carotenoids, lecithin, and long-chain alcohols. The $\gamma$-oryzanol and vita$\min \mathrm{E}$ are the main antioxidants in RB, and the $\gamma$-oryzanol levels are around 20 times higher than vitamin $\mathrm{E}$, varying according to the growing environment and rice genotypes $[14,15]$.

In the past few years, RB has gained attention for its hypocholesterolemic, anti-diabetic, anti-obesogenic, antioxidant, and anti-inflammatory effects, mitigating the risk factors for cardiovascular diseases. Such effects have been attributed mainly to $\gamma$-oryzanol [13, 16-19]. RB shows vast potential due to beneficial health effects, nutritional value, low cost, and easy availability, despite the RB is still under-used food for human consumption and poorly explored. Moreover, it can be readily incorporated into the diet as a food supplement, representing a natural therapeutic alternative that can avoid undesirable side effects compared to pharmaceutical drugs [11, 14].

Although the beneficial impact on health is well known, its effects on mitigating cardiac dysfunction have not yet been evaluated in obesity. Therefore, this study aimed to evaluate the effect of RB supplementation to a high-sugar fat on cardiac dysfunction in an experimental obesity model.

\section{Methods}

\section{Animals and experimental design}

Male Wistar rats $( \pm 325 \mathrm{~g})$ obtained from the Animal Center of Botucatu Medical School, Sao Paulo State University (UNESP, Botucatu, SP, Brazil) were randomly distributed into three groups ( $n=8$ per group): control diet (C), high-sugar fat diet (HSF), and high-sugar fat diet supplemented with RB (HSF+RB) for 20 weeks. HSF groups also received $25 \%$ sucrose in drinking water, whereas normal drinking water without any supplementation was given to $\mathrm{C}$ rats. The animals were housed in individual cages under controlled temperature $\left(22 \pm 3{ }^{\circ} \mathrm{C}\right)$, luminosity $(12 \mathrm{~h}$ light/ dark cycle) and humidity $(60 \pm 5 \%)$, and received diets and water ad libitum.
At the end of the experimental period, following the echocardiogram and systolic blood pressure evaluation, the animals were fasted for $8 \mathrm{~h}$ and then anesthetized (thiopental $120 \mathrm{mg} / \mathrm{kg} / \mathrm{i}$.p.) and euthanized by decapitation after verification of the absence of foot reflex. Blood samples were collected, and the plasma was separated by centrifugation $\left(800 \times g\right.$ at $4{ }^{\circ} \mathrm{C}$ for $\left.10 \mathrm{~min}\right)$ for metabolic and hormonal analyzes. The adipose tissue was isolated, dissected, and weighed for nutritional profile assessment. Fresh feces and cardiac tissue were also collected from each animal for further analysis.

The study was performed according to the guidelines for animal research [20] and approved by the Ethics Committee on Animal Experiments of the Botucatu Medical School, UNESP (protocol number 1305/2019).

\section{Diet composition}

All the diets used in this experiment were nutritionally balanced for micronutrients but different for macronutrients. The ingredients and nutritional composition of the diets are presented in Table 1 . The $\mathrm{C}$ and HSF diets were previously described [21-23]. RB was gently provided by Brasília Alimentos Ltda (Santa Cruz do Rio Pardo, São Paulo, Brazil) and obtained from Oryza sativa $L$. rice processing. The RB was heat-stabilized to inactivate the enzymes responsible for the degradation of its components and prevent rancidity before being mixed with the other ingredients for the diet preparations [11, 24]. The HSF + RB diet was customized containing $11 \%(\mathrm{wt} / \mathrm{wt})$ of RB [25].

\section{Nutritional profile}

The nutritional profile of the animals was assessed according to the following parameters: food and caloric intake, water intake, body weight, body fat, adiposity index, and fecal fat. Food and water intake were daily calculated from the individual leftovers of each animal, and the caloric intake was determined by multiplying the energy value of each diet ( $g$ $\times$ Kcal) by the daily food consumption. For the groups fed the HSF diet, the caloric intake also included the calories from the sucrose in drinking water. The body weight was measured weekly. The body fat was determined by the sum of epididymal, retroperitoneal, and visceral fat pad weights. The adiposity index was calculated as follows: [body fat (g)/ final weight $(\mathrm{g})] \times 100$. The fecal fat content was assessed by the acid steatocrit method [26]. Briefly, random spots from the fresh feces were collected, and $0.5 \mathrm{~g}$ was diluted in water, homogenized, and then mixed with perchloric acid $5 \mathrm{M}$. The mixture was aspirated into a capillary tube, and one end was sealed and centrifuged in a centrifuge for capillary tubes $(10,000 \times g, 15 \mathrm{~min})$. The fat and solid layers were measured, 
Table 1 Ingredients and nutritional composition of diets

\begin{tabular}{|c|c|c|c|}
\hline Components (g/kg) & $\mathrm{C}$ & HSF & $\mathrm{HSF}+\mathrm{RB}$ \\
\hline Soybean meal & 335 & 340 & 340 \\
\hline Sorghum & 278 & 80 & 80 \\
\hline Soy hulls & 188 & 116 & 6 \\
\hline Dextrin & 146 & 20 & 20 \\
\hline Sucrose & - & 80 & 80 \\
\hline Fructose & - & 180 & 180 \\
\hline Soybean oil & 23 & - & - \\
\hline Lard & - & 154 & 154 \\
\hline Rice bran & - & - & 110 \\
\hline Vitamin and mineral premix & 25 & 25 & 25 \\
\hline Salt & 4 & 8 & 8 \\
\hline \multicolumn{4}{|l|}{ Nutritional values } \\
\hline Carbohydrate (\% of ingredients) & 60.0 & $53.5 *$ & $55.1 *$ \\
\hline Protein (\% of ingredients) & 20.0 & 18.0 & 18.1 \\
\hline Fat (\% of ingredients) & 4.00 & 16.5 & 18.3 \\
\hline UFA & 69.0 & 47.0 & 62.0 \\
\hline SFA & 31.0 & 53.0 & 38.0 \\
\hline Others $(\%)^{* *}$ & 16.0 & 12.0 & 8.50 \\
\hline Carbohydrates (\% calories) & 66.8 & $49.2 *$ & $48.3 *$ \\
\hline Protein (\% calories) & 22.9 & 16.6 & 15.8 \\
\hline Fat $(\%$ calories $)$ & 10.4 & 34.2 & 35.9 \\
\hline Energy (Kcal/g) & 3.59 & $4.35^{*}$ & $4.58 *$ \\
\hline
\end{tabular}

$C$ control diet; $H S F$ high-sugar fat diet; $R B$ rice bran; $U F A$ unsaturated fatty acids; $S F A$ saturated fatty acids

$* \%$ of carbohydrate and energy in chow without considering the sucrose added in drinking water

**Ashes and fibers

and the acid steatocrit was calculated by the formula: fat layer/(fat layer + solid layer) $\times 100$ [27].

\section{Metabolic and hormonal analysis in plasma}

Triglycerides concentrations were measured using specific kits (BIOCLIN ${ }^{\circledR}$, Belo Horizonte, MG, Brazil) and analyzed by a colorimetric-enzymatic method in an automatic enzymatic analyzer system (Chemistry Analyzer BS-200, MindrayMedical International Limited, Shenzhen, China). The glucose level was measured in a blood drop using a handheld glucometer (Accu-Chek Performa, Roche Diagnostics Brazil Limited, SP, Brazil). The insulin levels were evaluated by an enzyme-linked immunosorbent assay (ELISA) method (EMD Millipore Corporation, Billerica, MA, USA), according to the manufacturer's instructions, and the reading was recorded using a microplate reader (Spectra Max 190, Molecular Devices ${ }^{\circledR}$, Sunnyvale, CA, USA). Insulin resistance was estimated according to the homeostatic model assessment for insulin resistance
(HOMA-IR) index using the following formula: fasting insulin $(\mu \mathrm{U} / \mathrm{mL}) \times$ fasting glucose $(\mathrm{mmol} / \mathrm{L}) / 22.5$.

\section{Cardiovascular profile}

\section{Systolic blood pressure}

The systolic blood pressure (SBP) analysis was assessed in conscious rats by a non-invasive tail-cuff method with a NarcoBioSystems ${ }^{\circledR}$ Electro-Sphygmomanometer (International Biomedical, Austin, TX, USA). The animals were warmed in a wooden box $(50 \times 40 \mathrm{~cm})$ between 38 and $40{ }^{\circ} \mathrm{C}$ for $4 \mathrm{~min}$ to stimulate arterial vasodilation. After this procedure, a cuff with a pneumatic pulse sensor was attached to the tail of the animal. The cuff was inflated to $200 \mathrm{mmHg}$ pressure and subsequently deflated. The arterial pulsations were recorded in a computerized data acquisition system (AcqKnowledge ${ }^{\circledR}$ MP100, Biopac Systems Inc., Santa Barbara, CA, USA). The average of three pressure readings was obtained for each animal [28]. 


\section{Echocardiographic study}

Doppler echocardiographic evaluation was performed by a single examiner using commercially available echocardiography (General Electric Medical Systems, Vivid S6, Tirat Carmel, Israel) equipped with a 5-11.5 MHz multifrequency ultrasonic transducer. Animals were anesthetized via intraperitoneal injection of a mixture of ketamine $(50 \mathrm{mg} / \mathrm{kg})$ and xylazine hydrochloride $(1 \mathrm{mg} / \mathrm{kg})$. After trichotomy of the anterior chest region, the animals were placed in slight left lateral decubitus for the exam. For structural measurements of the heart, the images were obtained in one-dimensional mode (M-mode) guided by the images in two-dimensional mode with the transducer in the parasternal position, minor axis. Left ventricular (LV) evaluation was performed by positioning the cursor M-mode just below the mitral valve plane at the papillary muscles level. The images of the aorta and left atrium were obtained by positioning the M-mode course to plan the aortic valve level.

The following LV structural parameters were analyzed: diameters of the left atrium (LA) and aorta (AO), LV diastolic diameter (LVDD), and LV relative wall thickness (RWT). The LV systolic function was assessed by ejection fraction (EF), posterior wall shortening velocity (PWSV), and tissue Doppler imaging (TDI) of mitral annulus systolic velocity ( $\left.\mathrm{S}^{\prime}\right)$. The LV diastolic function was evaluated by early and late diastolic mitral inflow velocities (E and A waves), E/A ratio, E wave deceleration time (EDT), TDI of early (E') and late (A') mitral annulus diastolic velocity (average of septal and lateral walls), and E'/A' and E/E' ratios [29].

\section{Inflammation and redox state in myocardium}

Tissue preparation The LV samples were homogenized in phosphate-buffered saline (PBS) pH 7.4 (1:10; w/v) using a bead beater homogenizer (Bullet Blender ${ }^{\circledR}$, Next Advance, Inc., NY, USA). The homogenates were centrifuged at $800 \times g$ for $10 \mathrm{~min}$ at $4{ }^{\circ} \mathrm{C}$ (Eppendorf ${ }^{\circledR}$ Centrifuge 5804$\mathrm{R}$, Hamburg, Germany), and the supernatant was obtained to measure the pro-inflammatory cytokines and redox state, such as antioxidant enzymes activity and oxidative markers. All the analyses were normalized by the total protein content, which was determined using a colorimetric method (BioClin, Quibasa Química Básica Ltda., Belo Horizonte, MG, Brazil), and the readings were performed in a microplate reader.

Pro-inflammatory cytokines Interleukin-6 (IL-6) and tumoral necrosis factor alpha (TNF- $\alpha$ ) were assessed by ELISA assay (EMD Millipore Corporation, Billerica, MA, USA), according to manufactures' instructions, and the readings were performed in a microplate reader.
Antioxidant enzymes activity Superoxide dismutase (SOD) activity was measured based on the inhibition of superoxide radical reaction with pyrogallol by spectrophotometry at $420 \mathrm{~nm}$. One unity of SOD activity (U) is defined as the quantify of the enzyme that inhibited $50 \%$ of pyrogallol autoxidation, and the results were expressed in U/mg protein/minute [30].

Catalase (CAT) activity was evaluated by the decrease in hydrogen peroxide $\left(\mathrm{H}_{2} \mathrm{O}_{2}\right)$ levels. The breakdown of $\mathrm{H}_{2} \mathrm{O}_{2}$ in the reaction mixture was measured spectrophotometrically at $240 \mathrm{~nm}$, and the results were expressed as pmol/mg protein/ minute [31].

Glutathione peroxidase (GPx) activity was assessed spectrophotometrically at $340 \mathrm{~nm}$ by following $\beta$-nicotinamide adenine dinucleotide phosphate (NADPH) oxidation as described by Flohé and Günzler (1984) [32]. The enzymatic activity was expressed as $\mu \mathrm{mol} / \mathrm{mg}$ protein/minute.

Oxidative stress markers Protein carbonylation (CBO) was measured in the supernatant by a photometric assay using DNPH (2,4-dinitrophenyl hydrazine) as derivatizing agent [33]. All the procedures were performed protected from light. The supernatant previously prepared was diluted (1:10), and then $10 \mu \mathrm{l}$ was incubated with $100 \mu \mathrm{l}$ of $10 \mathrm{mM}$ DNPH solution for $10 \mathrm{~min}$. Following this, $50 \mu \mathrm{l}$ of $6 \mathrm{M}$ $\mathrm{NaOH}$ (sodium hydroxide) was added and incubated for $10 \mathrm{~min}$. Absorbance was recorded spectrophotometrically at $450 \mathrm{~nm}$. The results were calculated with molar extinction coefficient $\left(22,000 \mathrm{M}^{-1} \mathrm{~cm}^{-1}\right)$ of DNPH, and expressed as $\mathrm{nmol} / \mathrm{mg}$ protein.

Malondialdehyde (MDA) concentrations were measured to estimate lipid peroxidation levels. The samples were mixed with $10 \%$ trichloroacetic acid (TCA) for protein precipitation in the proportion 1:4 (sample: TCA). After centrifugation $(800 \times g, 5 \mathrm{~min})$, the supernatant was removed, and $0,67 \%$ thiobarbituric acid (TBA) was added (1:1). Then, the samples were heated for $15 \mathrm{~min}$ at $100{ }^{\circ} \mathrm{C}$, and after cooling, the absorbance readings were acquired using spectrophotometer at $535 \mathrm{~nm}$. The MDA concentration was obtained by the molar extinction coefficient $\left(1.56 \times 10^{5} \mathrm{M}^{-1} \mathrm{~cm}^{-1}\right)$, and expressed in $\mathrm{nmol} / \mathrm{mg}$ protein [34].

\section{Statistical analysis}

The data were tested for normality using the Shapiro-Wilk test and for homogeneity of variance using Levene's test prior to statistical analysis. The data were compared by oneway ANOVA followed by Tukey post-hoc test for parametric data or Kruskal-Wallis followed by Dunn's post-hoc test for non-parametric data. Data were expressed as mean \pm standard deviation (SD) or median \{minimum [min]-maximum $[\max ]\}$. 
All numerical biological results were analyzed using a web tool for visualizing the clustering of multivariate data ClustVis [35] for exploring the unsupervised multivariate principal component analysis (PCA) and hierarchical clustering analyses. The correlation matrix with all data was analyzed using a 2-tailed Pearson's correlation test.

The analyses were performed using SigmaPlot 12.0 for Windows (Systat Software Inc., San Jose, CA, USA). All graphics were generated using GraphPad Prism 8 (GraphPad Software Inc., San Diego, CA, USA). The differences were considered statistically significant when $p<0.05$.

\section{Results}

\section{Rice bran supplementation prevented weight gain and increased fecal fat}

Body weight gain mainly depends on food and calorie intake, and such information provides insights into the progression of obesity. The HSF and HSF + RB groups presented a decrease in food intake accompanied by increased water and calorie intake compared to the $\mathrm{C}$ group. In addition, there is no interference of RB in food, water, and calorie intake since these parameters were similar between HSF and HSF + RB groups (Table 2). Prolonged exposure to HSF caused a significant rise in body weight, body fat, and adiposity index, leading the animals to obesity (Fig. 1A-C). RB was able to prevent the weight
Table 2 Dietary intake of the control diet (C), high-sugar fat diet (HSF), and high-sugar fat diet supplemented with rice bran $(\mathrm{HSF}+\mathrm{RB})$ groups
Fig. 1 Nutritional profile. (A) Body weight, (B) body fat, (C) adiposity index, and (D) acid steatocrit of the control diet (C), high-sugar fat diet (HSF), and high-sugar fat diet supplemented with rice bran $(\mathrm{HSF}+\mathrm{RB})$ groups. Data expressed as median (min$\max )$. Mean is indicated as + . ${ }^{*} p<0.05$. ANOVA followed by Tukey for A, B, C and D

\begin{tabular}{llll}
\hline Variables & $\mathrm{C}$ & HSF & HSF + RB \\
\hline Food intake (g/day) & $22.8(20.3-24.2)$ & $12.3(11.9-12.8)^{*}$ & $11.0(9.21-13.0)^{*}$ \\
Water intake (mL/day) & $32.4 \pm 5.22$ & $51.6 \pm 8.07^{*}$ & $50.5 \pm 7.93^{*}$ \\
Caloric intake (kcal/day) & $81.3 \pm 4.82$ & $105 \pm 6.53^{*}$ & $101 \pm 2.77^{*}$ \\
\hline
\end{tabular}

Data expressed in mean \pm SD or median (min-max) compared by one-way ANOVA followed by Tukey post-hoc or Kruskal Wallis followed by Dunn's post-hoc test $p<0.05: * \mathrm{vs} \mathrm{C}$
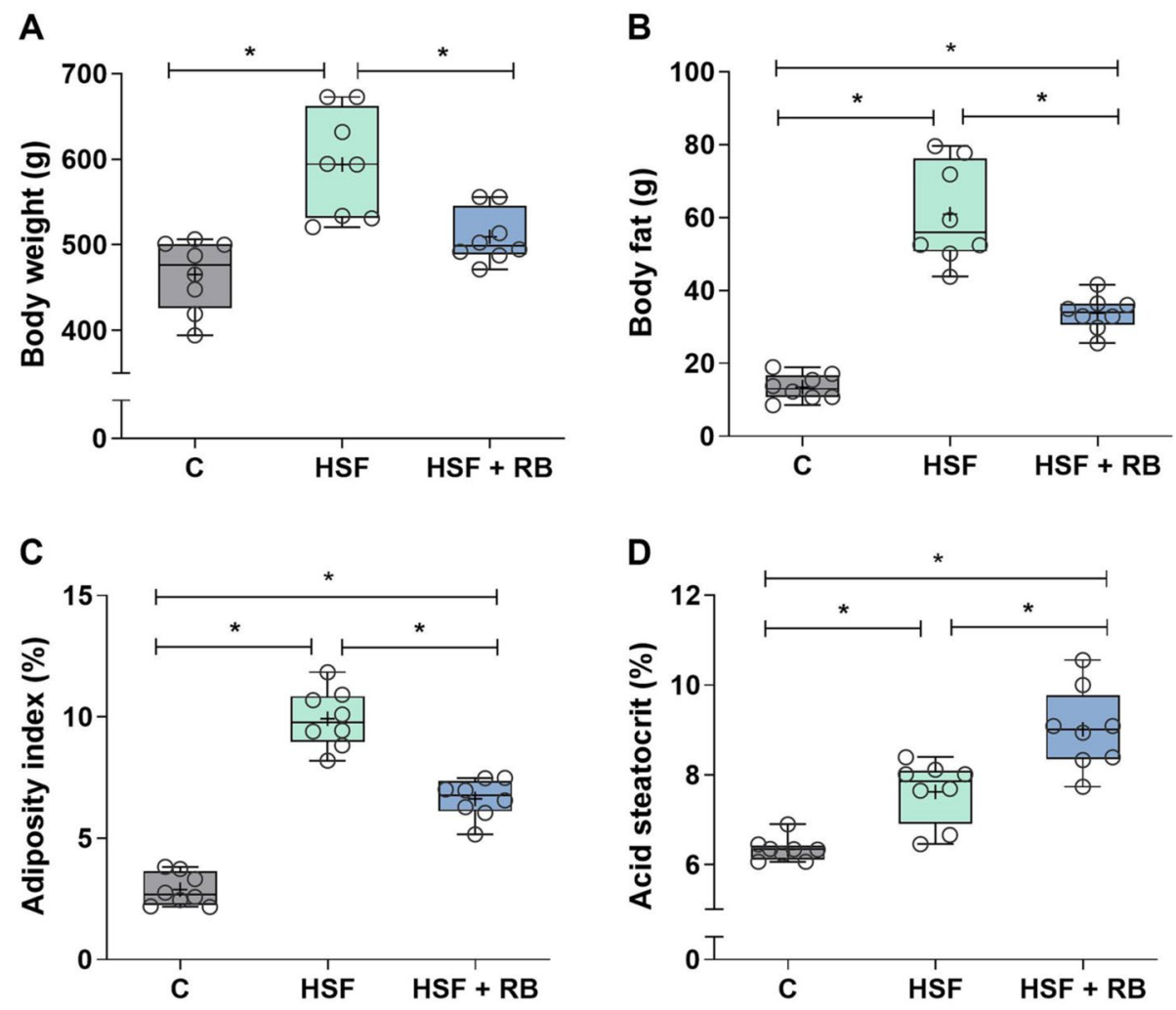
gain in the rats fed HSF since there is no difference in body weight between $\mathrm{HSF}+\mathrm{RB}$ and $\mathrm{C}$ groups (Fig. 1A). Although the body fat and adiposity index remained higher in the HSF + RB animals compared to the $\mathrm{C}$ group, these parameters showed a significant decrease, of $44.6 \%$ and $33.3 \%$, respectively, in the rats fed HSF supplemented with $\mathrm{RB}$ in relation to animals under the HSF but without supplementation (Figs. 1B and C). The acid steatocrit values were statistically different comparing the three groups, and RB led to higher excretion of the fecal fat in the animals (Fig. 1D).

\section{Insulin resistance and lipid profile changes are prevented by RB supplementation}

HSF diet-induced obesity promoted significant metabolic and hormonal changes (Fig. 2). The plasma triglycerides, glucose, and insulin levels and HOMA-IR were higher in HSF rats than in $\mathrm{C}$ rats (Fig. 2A-D). Although the plasma triglycerides remain elevated in the $\mathrm{HSF}+\mathrm{RB}$ animals in relation to the $\mathrm{C}$ group, these values were $43.4 \%$ lower in $\mathrm{HSF}+\mathrm{RB}$ group compared to the HSF group (Fig. 2A). Additionally, the elevation of glucose and insulin levels was prevented by RB supplementation in animals fed HSF since the values were similar to $\mathrm{C}$ group (Figs. 2B and $\mathrm{C}$ ), as well as the insulin resistance, assessed by HOMA-IR (Fig. 2D), a marker of metabolic homeostasis.

\section{RB supplementation preserves cardiac structure and function in rats fed HSF}

The SBP and cardiac structural and functional data, evaluated by echocardiogram, are shown in Table 3. The SBP was elevated in HSF and HSF + RB groups compared to the $\mathrm{C}$ group, and RB supplementation did not change this condition in relation to animals fed HSF diet without RB. HSF-induced obese rats presented structural changes (LA, LA/AO, LVDD, and RWT) and systolic (EF, PWSV, and S' media) and diastolic (EDT, E/E', and E'/A') dysfunction compared to the $\mathrm{C}$ group. All these cardiac structural and functional parameters were preserved by RB supplementation in animals fed HSF, suggesting the potential of the RB in preventing cardiac disorders in the obesity model.

\section{RB mitigated IL- 6 and TNF-a levels in heart tissue}

Inflammation is an important obesity-related disorder, and to verify the preventive effect of $\mathrm{RB}$ on this condition in a HSF-induced obesity model, we evaluated the pro-inflammatory cytokines, as IL- 6 and TNF- $\alpha$, in the heart tissue. The obesity due to the HSF diet caused cardiac inflammation, observed by elevated IL-6 and TNF- $\alpha$ cytokine (Fig. 3A and $\mathrm{B})$. The RB supplementation was able to prevent the rise of IL-6 in rats fed HSF since the values were similar to the rats fed $\mathrm{C}$ diet (Fig. 3A). In contrast, the $\mathrm{HSF}+\mathrm{RB}$ group showed higher levels of TNF- $\alpha$ compared to the $\mathrm{C}$
Fig. 2 Plasma metabolic and hormonal analyses. (A) Triglycerides, (B) glucose, $(\mathbf{C})$ insulin, and (D) homeostatic model assessment of insulin resistance (HOMA-IR) index of the control diet $(\mathbf{C})$, high-sugar fat diet (HSF), and high-sugar fat diet supplemented with rice bran (HSF + RB) groups. Data expressed as median (minmax). Mean is indicated as + . $* p<0.05$. ANOVA followed by Tukey for A, C and D; KruskalWallis followed by Dunn's for B
A

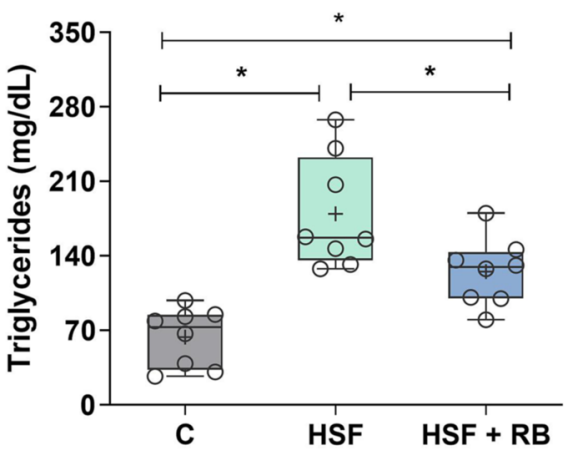

C

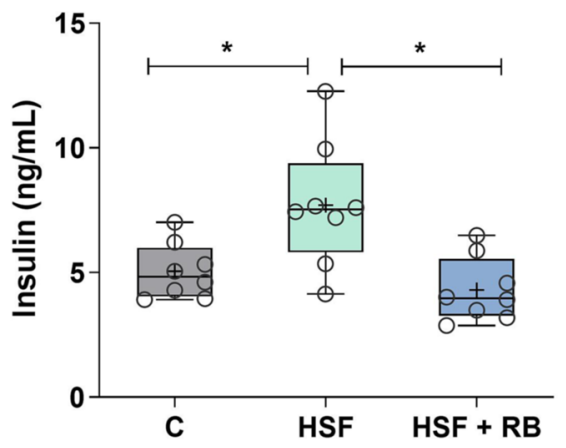

B

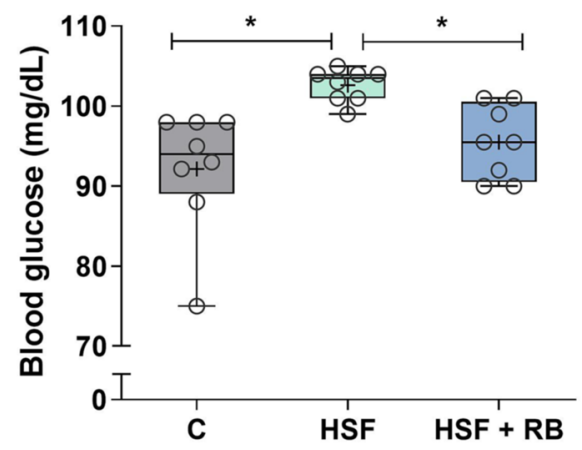

D

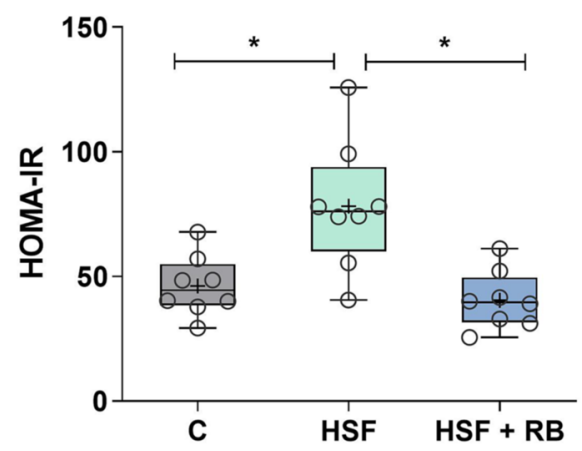


Table 3 Systolic blood pressure (SBP) and echocardiography study of the control diet (C), high-sugar fat diet (HSF), and high-sugar fat diet supplemented with rice bran $(\mathrm{HSF}+\mathrm{RB})$ groups

\begin{tabular}{llll}
\hline Variables & C & HSF & HSF + RB \\
\hline SBP $(\mathrm{mmHg})$ & $123 \pm 4.94$ & $140 \pm 9.27^{*}$ & $137 \pm 5.02^{*}$ \\
HR $(\mathrm{bpm})$ & $228(208-271)$ & $285(118-369)$ & $254(150-312)$ \\
LA $(\mathrm{mm})$ & $4.60(4.60-$ & $5.75(5.36-$ & $4.85(4.70-$ \\
& $4.85)$ & $6.39)^{*}$ & $4.90)^{\#}$ \\
AO $(\mathrm{mm})$ & $3.83(3.58-$ & $3.70(3.32-$ & $4.09(3.58-4.09)$ \\
& $3.83)$ & $4.34)$ & \\
LA/AO & $1.23(1.20-$ & $1.53(1.23-$ & $1.19(1.18-$ \\
& $1.35)$ & $1.77)^{*}$ & $1.31)^{\#}$ \\
LVDD $(\mathrm{mm})$ & $7.49 \pm 0.49$ & $6.78 \pm 0.33^{*}$ & $7.41 \pm 0.44^{\#}$ \\
RWT & $0.39 \pm 0.00$ & $0.55 \pm 0.05^{*}$ & $0.41 \pm 0.02^{\#}$ \\
EF $(\%)$ & $0.93 \pm 0.00$ & $0.89 \pm 0.02^{*}$ & $0.92 \pm 0.01^{\#}$ \\
PWSV $(\mathrm{cm} / \mathrm{s})$ & $74.5 \pm 5.60$ & $66.2 \pm 6.83^{*}$ & $75.8 \pm 5.59^{\#}$ \\
S' media $(\mathrm{cm} / \mathrm{s})$ & $5.48 \pm 0.11$ & $4.93 \pm 0.19^{*}$ & $5.53 \pm 0,25^{\#}$ \\
E wave $(\mathrm{cm} / \mathrm{s})$ & $73.3 \pm 8.37$ & $81.7 \pm 6.64$ & $76.9 \pm 3.78$ \\
E/A & $1.74 \pm 0.36$ & $1.65 \pm 0.40$ & $1.89 \pm 0.44$ \\
EDT (ms) & $48.7 \pm 3.53$ & $58.3 \pm 4.26^{*}$ & $48.8 \pm 3.68^{\#}$ \\
E'/A' & $1.62(1.39-$ & $0.63(0.58-$ & $1.52(1.29-$ \\
& $1.70)$ & $1.89)^{*}$ & $1.81)^{\#}$ \\
E/E' & $14.0(11.1-$ & $23.4(28.2-$ & $14.1(13.2-$ \\
& $15.5)$ & $16.8)^{*}$ & $15.2)^{\#}$ \\
\hline & & &
\end{tabular}

Data expressed in mean \pm SD or median (min-max) compared by one-way ANOVA followed by Tukey post-hoc or Kruskal Wallis followed by Dunn's post-hoc

$S B P$ systolic blood pressure; $H R$ heart rate; $L A$ left atrium diameter; $A O$ aorta diameter; $L V D D$ left ventricle (LV) diastolic diameter; $R W T$ LV relative wall thickness; $E F$ ejection fraction; $P W S V$ posterior wall shortening velocity; $S$ ' tissue Doppler imaging (TDI) of mitral annulus systolic velocity; $E$ early diastolic mitral inflow velocity; $A$ late diastolic mitral inflow velocity; $E D T \mathrm{E}$ wave deceleration time; $E$, TDI of early mitral annulus diastolic velocity; $A^{\prime}$ TDI of late mitral annulus diastolic velocity

$p<0.05: *$ vs C; \#vs HSF

group, despite mitigating the elevation of this cytokine by presenting a lower concentration concerning the HSF group (Fig. 3B).

\section{RB supplementation prevents redox imbalance in heart tissue of HSF-fed rats}

The activity of antioxidant defense enzymes and pro-oxidant markers were measured to evaluate the preventive effect of $\mathrm{RB}$ in the cardiac redox state of the rats with HSF-induced obesity (Fig. 4). The antioxidant enzyme activities, SOD and CAT, were decreased in HSF group compared to the C animals. Both enzymes were significantly restored by RB supplementation in the HSF + BR group to similar levels of $\mathrm{C}$ rats. There was no difference in GPx activity comparing all groups. Concerning the oxidative stress markers, only the MDA levels were affected by obesity since the HSFfed animals showed higher values than $\mathrm{C}$ rats. Moreover, the $\mathrm{HSF}+\mathrm{RB}$ group was able to maintain this parameter at levels similar to the $\mathrm{C}$ group and lower than the HSF group.

\section{Global correlation map, multivariate and clustering analyses}

A correlation matrix via Pearson's correlation was performed to correlate cardiac structure and function parameters with other variables assessed (Fig. 5). The cardiac structural and functional variables were significantly correlated to body fat and adiposity index, negatively or positively, showing a more substantial influence of adiposity than body weight. As the body fat and adiposity index increases, the structure variables rise as well, except LVDD. The systolic function parameters decrease as the body fat and adiposity index increase. The acid steatocrit did not show a correlation to the cardiac parameters. The biochemical and metabolic variables, triglycerides, glucose, insulin, and HOMA-IR were correlated to most cardiac variables. Cardiac biomarkers of inflammation and oxidative stress were also associated with cardiac structure and function. IL-6 and TNF-a demonstrated a positive correlation with LA, LA/AO, RWT, EDT, and E/E' and were inversely related to E'/A'. Moreover, TNF- $\alpha$ was also inversely related to LVDD, EF, and S' media. The antioxidant enzymes, SOD and CAT, presented an inverse correlation to the other parameters, as
Fig. 3 Pro-inflammatory cytokines in cardiac tissue. (A) Interleukin-6 (IL-6) and (B) tumoral necrosis factor alpha (TNF- $\alpha$ ) levels of the control diet $(\mathbf{C})$, high-sugar fat diet (HSF), and high-sugar fat diet supplemented with rice bran $(\mathrm{HSF}+\mathrm{RB})$ groups. Data expressed as median ( $\mathrm{min}-$ $\max$ ). Mean is indicated as + . ${ }^{*} p<0.05$. ANOVA followed by Tukey for B; Kruskal-Wallis followed by Dunn's for A
A

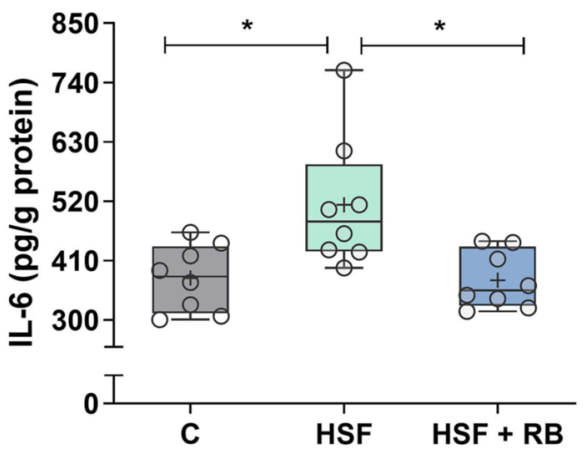

B

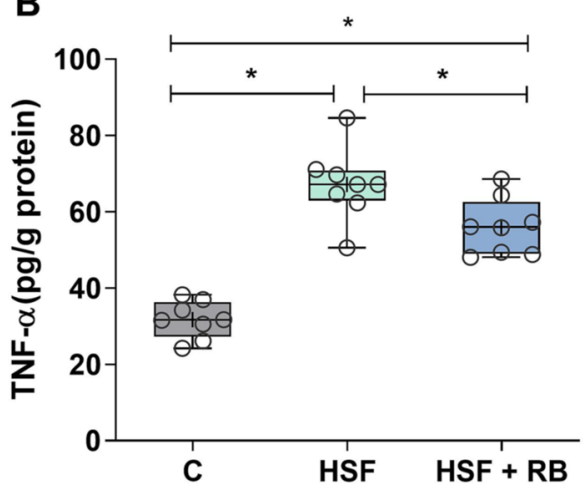


Fig. 4 Antioxidant enzyme activities and oxidative markers in cardiac tissue. (A) Superoxide dismutase (SOD), (B) catalase (CAT), and (C) glutathione peroxidase (GPx) activities and (D) protein carbonylation (CBO) and (E) malondialdehyde (MDA) levels of the control diet (C), high-sugar fat diet (HSF), and high-sugar fat diet supplemented with rice bran $(\mathrm{HSF}+\mathrm{RB})$ groups. Data expressed as median (min$\max$ ). Mean is indicated as + . $* p<0.05$. ANOVA followed by Tukey for $\mathbf{A}, \mathbf{B}, \mathbf{C}$ and $\mathbf{D}$; Kruskal-Wallis followed by Dunn's for $\mathbf{E}$
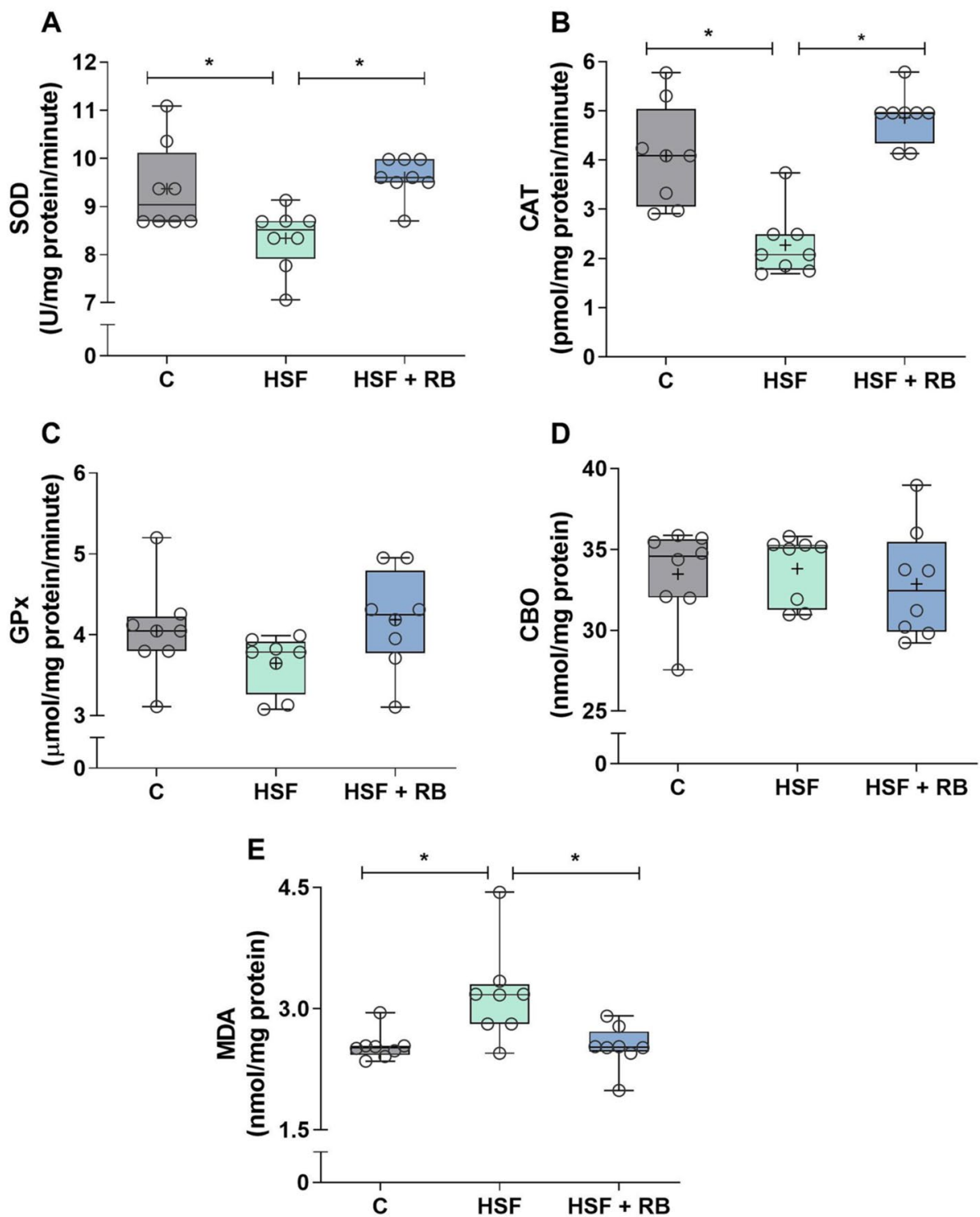

expected since the enzymes act in the opposite direction preventing the cardiac changes. CAT showed significance to all cardiac parameters.

Unsupervised multivariate principal component analysis (PCA) (Fig. 6A) and hierarchical cluster analysis (Fig. 6B) indicates a very well separation of the groups. In both analysis, HSF group is clustered away from $\mathrm{C}$ group indicating the efficiency of the model to induce the changes. The HSF + RB group is placed between the other two groups, closer to $\mathrm{C}$ group than HSF, indicating the beneficial effect of RB to prevent the changes induced in HSF group.

\section{Discussion}

The dietary pattern high in saturated fat and sugars, known as the Western diet, dramatically influences the body composition, the development of metabolic complications, and cardiovascular diseases (CVDs). CVDs represents 17.9 million deaths annually [36]. Therefore, it is crucial to investigate alternatives to mitigate the consequences of excess adipose tissue, mainly non-pharmacological prevention strategies. The incorporation of natural foods into 


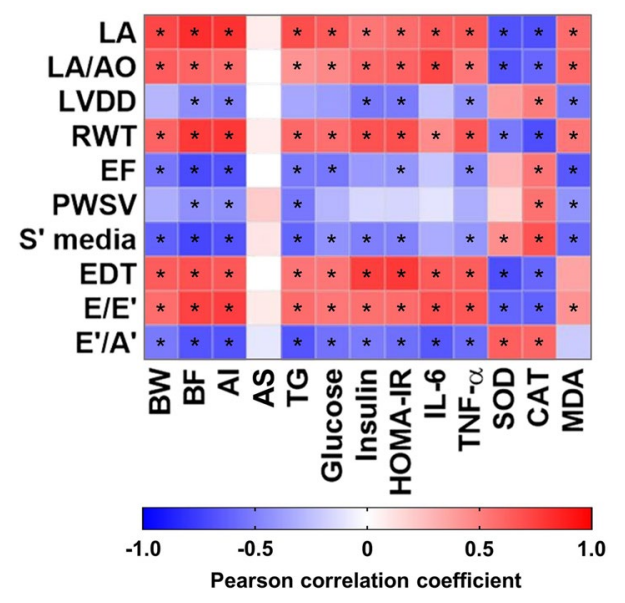

Fig. 5 Correlation among structural and functional cardiac data and nutritional, metabolic, hormonal, inflammatory, and oxidative profiles visualized by a heatmap. $L A$ left atrium diameter; $A O$ aorta diameter; $L V D D$ left ventricle (LV) diastolic diameter; $R W T$ LV relative wall thickness; $E F$ ejection fraction; $P W S V$ posterior wall shortening velocity; $S$ ' tissue Doppler imaging (TDI) of mitral annulus systolic velocity; $E D T \mathrm{E}$ wave deceleration time; $E$ early diastolic mitral inflow velocity; $E$ ' TDI of early mitral annulus diastolic velocity; $A$ ' TDI of late mitral annulus diastolic velocity; $B W$ body weight; $B F$ body fat; $A I$ adiposity index; $A S$ acid steatocrit; $T G$ triglycerides; $I L$ 6 interleukin-6; $T N F-\alpha$ tumoral necrosis factor alpha; SOD superoxide dismutase; $C A T$ catalase and $M D A$ malondialdehyde. Data of all experimental groups were gathered and analyzed by GraphPad Prism 8 software using a 2-tailed Pearson's correlation test. As shown by the color scale, the blue color indicates a negative correlation, while the red color indicates a positive correlation. The symbol $*$ indicates a statistically significant correlation $(p<0.05)$

the diet with beneficial effects has been extensively evaluated as an alternative. The expressive amount of bioactive compounds presents in plant foods and their synergistic effect can act as a preventive agent [37]. In this context, this study aimed to evaluate the effect of RB supplementation in a high-sugar fat diet on cardiac dysfunction in an experimental obesity model. Our results revealed that dietary RB supplementation promoted amelioration of systemic metabolic complications, cardiac dysfunction, and inflammation and redox imbalance in the myocardium in a diet-induced obesity model (Fig. 7).

In a condition of positive energy balance, hypertrophy of adipocytes and hyperplasia of preadipocytes occur to store the energy in the form of triglycerides [38]. Although these processes are physiologically necessary, hypertrophy is mainly associated with adipose tissue dysfunction, resulting in adipocyte inability to store triglycerides and imbalance of adipokine secretion, leading to excessive production of reactive oxygen species (ROS) and pro-inflammatory cytokines. These factors lead to insulin resistance, redox imbalance, and chronic inflammation, which serve as a trigger for developing metabolic and cardiovascular complications [38-40]. Our findings showed that the rats that
A

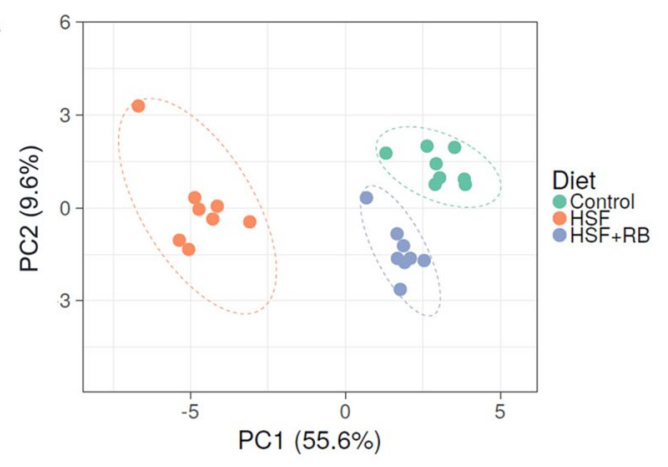

B

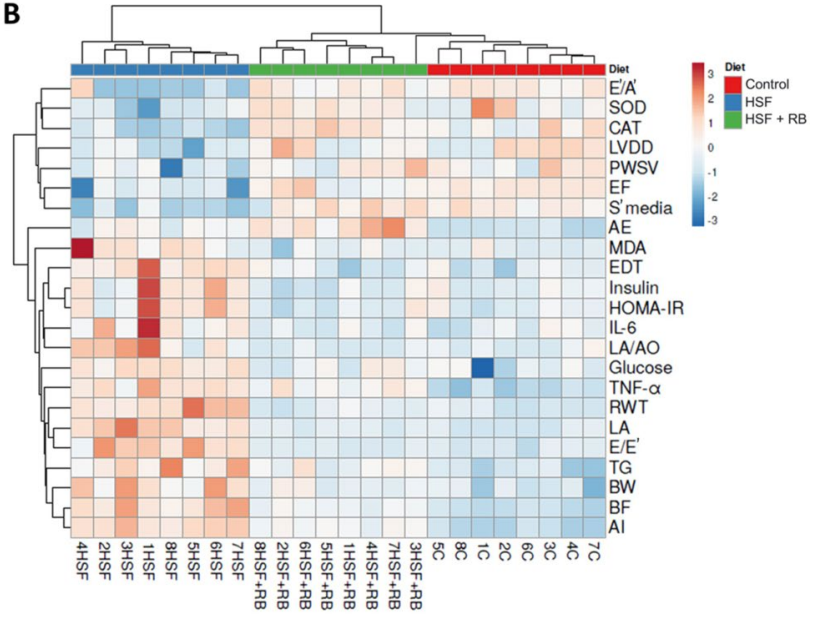

Fig. 6 (A) Unsupervised multivariate principal component analysis (PCA) plot showing the multivariate variation among control, highsugar fat (HSF), and high-sugar fat supplemented with rice bran $(\mathrm{HSF}+\mathrm{RB})$ diets in relation to all evaluated parameters. Each data point represents a sample, which is colored by the annotation of its diet type. (B) Hierarchical clustering analyses (Heatmap) using unsupervised Euclidean distance summarizes the effect of rice bran (RB) on the studied parameters of rats fed on a high-sugar fat diet (HSF). All evaluated parameters abbreviations are as defined in Fig. 5

received RB supplementation did not accumulate fat and increase their body weight in the same proportion as the HSF group. This fact probably attenuated the adipose tissue role in the complications. Previous studies attributed some mechanisms, which may be involved in the anti-obesogenic and antilipidemic effect of RB. Firstly, one plausive explanation would be the ability of RB to provide a more significant elimination of fat in the feces due to the fiber content and the $\gamma$-oryzanol [41]. Another factor is its effect on lipid metabolism, preventing fat accumulation and decreasing body weight and adiposity index. Moreover, RB modulates gut microbiota decreasing the Firmicutes/Bacteroidetes ratio and the adipose tissue expression of uncoupling protein 1 (UCP1), peroxisome proliferator-activated receptor gamma coactivator 1-alpha (PGC 1- $\alpha$ ), and PR domain containing 16 (PRDM16), as well as increase the expression of peroxisome proliferator-activated receptor gamma (PPAR- $\gamma$ ), 


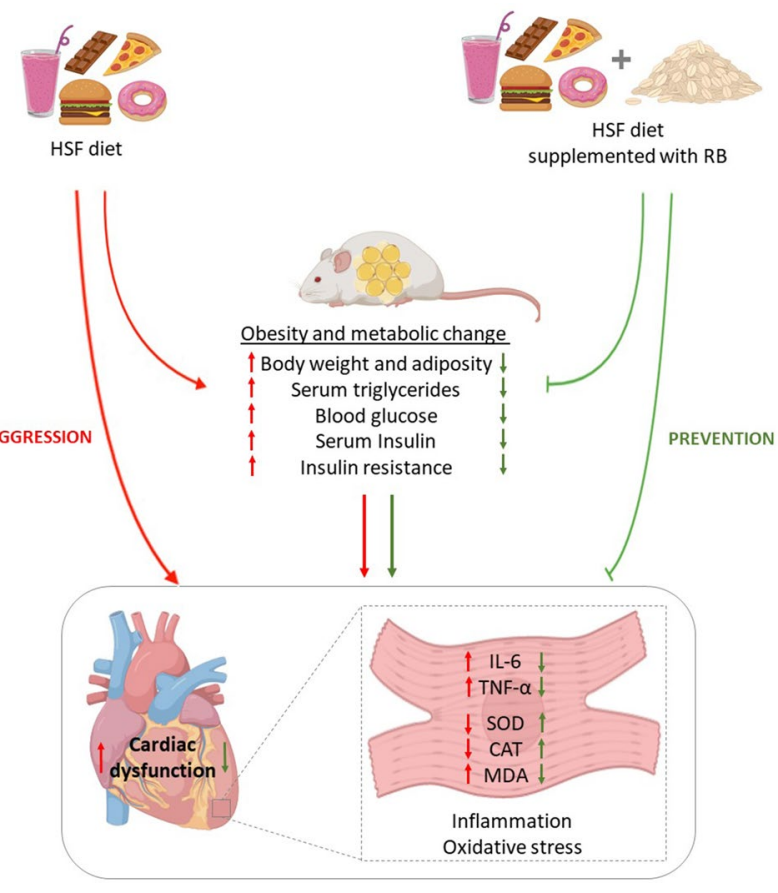

Fig. 7 Overview of the changes induced by HSF diet (red arrows) and preventive effect of RB supplementation (green arrows). The HSF intake increases body weight and adiposity (obesity), leads to metabolic changes, cardiac dysfunction, increase of IL- 6 and TNF- $\alpha$ levels in cardiac tissue and redox imbalance. The RB supplementation was able to prevent the metabolic changes, cardiac dysfunction, increase of cytokines and redox imbalance in cardiac tissue. $H S F$ high-sugar fat diet, $R B$ rice bran, $I L-6$ interleukin-6; TNF- $\alpha$ tumoral necrosis factor; $S O D$ superoxide dismutase; $C A T$ catalase and $M D A$ malondialdehyde

favoring adipocyte hyperplasia and relieving the lipid overload triggered by hypertrophy $[18,42,43]$.

The molecular mechanisms for the development of obesity-related glucose metabolism have also been researched [44]. Classic scientific evidence reports that inflammation due to adipose tissue expansion influences the intracellular pathway of insulin, causing damage in the translocation of GLUT4 to the plasma membrane by infusing the phosphorylation of insulin receptor substrates $[45,46]$. This information agrees with our results since the animals that consumed $\mathrm{HSF}+\mathrm{BR}$ stored $45 \%$ less body fat compared to the HSF group and possibly developed a lower hypertrophy degree and inflammation, which did not affect the glucose and insulin levels, thus not resulting in resistance to this hormone (Fig. 2B-D).

The diet-induced obesity model, as expected, presented relevant disruption in the cardiovascular system by developing hypertension, hypertrophy, and diastolic and systolic dysfunction. It is well known that obesity is associated with the cardiac remodeling in both humans and animal models, and several mechanisms are attributed to the functional impairment of the heart [47-50]. Our observations suggest the potential role of the inflammation and oxidative stress since HSF animals showed high levels of pro-inflammatory cytokines and an imbalance between antioxidant and prooxidant agents in cardiac tissue, which have been correlated with various parameters of cardiac function and structure (Fig. 5), corroborating previous studies [51]. Interestingly, RB supplementation prevented the development of structural and functional alteration and attenuated the pro-inflammatory and oxidative state in the heart of animals under HSF. In the literature, there are no studies that evaluated preventive RB supplementation on cardiac structure and function changes, except a work realized by our group [21], which showed that isolated $\gamma$-oryzanol significantly prevented structural and functional cardiac dysfunction in diet-induced obese animals for 20 weeks, but no via mechanistic target was evaluated. Here, our data suggested that RB was able to prevent the structural and functional cardiac impairment in obese animals, probably due to the mitigation of inflammatory and oxidative pathways. RB is comprised of a considerable number of phytochemicals with anti-inflammatory and antioxidant properties; among them, the $\gamma$-oryzanol is 13-20 times more in concentration compared to that of total tocotrienols and tocopherols in RB. Thus, it has gained special attention to their potential health benefits. The oil present in RB has been called the "Heart oil" since its chemical profile is considered as cardiac protective. Furthermore, the $\mathrm{RB}$ effect is associated with $\gamma$-oryzanol and not only with the fibers present in brans composition [14].

In relation to cardiac inflammation, we showed that obese rats supplemented with RB had lower cardiac IL-6 and TNF- $\alpha$ cytokines than obese animals without supplementation. Rao et al. [19] revealed that dietary $\gamma$-oryzanol of RB oil reduced pro-inflammatory mediators (IL-6 and TNF- $\alpha$ ) secreted by peritoneal macrophages of rats. Also, in other studies, serum TNF- $\alpha$ level was decreased in obese mice fed a high-fat diet supplemented with RB compared to obese mice [52], and $\gamma$-oryzanol significantly reduced the up-regulated expression of IL- $1 \beta$, IL- 6 , TNF- $\alpha$, and COX-2 mRNA in mice with colitis [53]. The mechanisms by which $\mathrm{RB}$ or its compounds decreases pro-inflammatory cytokine production are not yet fully understood and have been less studied. However, evidence has been pointed out for the role in decreasing levels of Toll-like Receptors (TLR-2 and TLR-4) and Nuclear Factor-kappa B (NF-кB) [19, 52-54] and up-regulating adiponectin expression, an important antiinflammatory marker [19].

The cardiac oxidative stress present in obese animals fed the HSF diet was affected by the RB supplementation inducing the rise in antioxidant enzymes, SOD and CAT, which may have influenced the decrease in MDA levels, ameliorating the pro-oxidant status in these animals. SOD, CAT, and GPx are the first line of enzyme-based cellular defense systems, and each enzyme displays a distinct role in the 
mitigation of oxidative injury, mainly combating ROS [55]. Investigations have shown that RB or their products and isolated compounds exert antioxidant properties by increasing the expression or activity of these antioxidant enzymes. Treatment with $\gamma$-oryzanol showed a significant protective antioxidant effect against oxidative stress in the glaucoma model for raising the down-regulated SOD, CAT, and GPx levels in this model [56]. The antioxidant cytoprotection effect of RB extract was also determined in rat H9c2(2-1) cardiomyocytes; the authors showed that RB elevated the enzymatic activity and gene expression of CAT [57]. The exact mechanism that allows these natural compounds to increase both expression and activity of antioxidant enzymes remains unclear; however, some studies evidence the association of this effect with nuclear factor erythroid 2-related factor 2 (Nrf2) pathway modulation [58]. Moreover, another antioxidant mechanism has also been proposed for the bioactive components of RB, e.g., their chemical structure that exhibit radical-scavenging activity [59].

Despite the promising results, limitations of this study include the lack of a deeper basic investigation to elucidate the molecular mechanisms and to confirm the potential pathways involved in the protective role of RB against cardiac dysfunction in obesity as discussed above. Additional research should better explore the underlying mechanisms of this effects so that clinical applications can be consider in the future.

Considering $\gamma$-oryzanol as the main compound in RB and its well-demonstrated antioxidant and anti-inflammatory activity, our results could be related to this. However, it is worth mentioning that the beneficial effects of RB supplementation on the heart, in addition to the possible direct action of its compounds, may also be due to the improvement of metabolic systemic parameters and reduction of body weight and fat.

Finally, we can emphasize that healthy eating habits are the primary step to prevent or to go along with medical treatment. However, the change of dietary pattern generates resistance from individuals; thus, reinforcing the inclusion of natural compounds in the usual diet, even before excluding harmful foods, already shows a positive result on health. Previous studies have shown dose translocation from experimental models to humans. In the present study, the RB dose in the diet was $11 \%(\mathrm{w} / \mathrm{w})$, and the average daily food intake (HSF + RB group) was $11.0 \mathrm{~g} /$ day/animal, which corresponds to $1.21 \mathrm{~g} /$ day of $\mathrm{RB}$. This is equivalent to $2.4 \mathrm{~g} / \mathrm{day} / \mathrm{kg}$, considering the average weight of the animals $(0.509 \mathrm{~kg})$. According to the formula in the literature, which considers the body surface area, the corresponding dose of RB is $31 \mathrm{~g} /$ day for a human of $60 \mathrm{~kg}(0.52 \mathrm{~g} /$ day/ $\mathrm{kg}$ ) [60-62]. The $31 \mathrm{~g}$ of $\mathrm{RB}$ is equivalent to 6 soup-spoons measurements, representing an amount that can be easily introduced in human consumption.
In conclusion, this investigation provides evidence that RB supplementation prevented cardiac dysfunction by modulating systemic metabolic complications and the inflammation and oxidative stress in the myocardium of obese rats fed HSF, suggesting that the regular consumption of RB could be an alternative dietary approach to combat obesity-related complications. Further studies are required to confirm the beneficial effect on humans in clinical trials involving large cohorts and longitudinal follow-up.

Author contributions Conceptualization: CRC, JLG and DHSC; data curation: CSG, AJTF and MRC; formal analysis: JLG, FVF, FM and SGZB; funding acquisition: CRC; investigation: IOM, FVF and MRC; methodology: JLG, CSG, SGZB and FM; software: JLG and DVF; writing — original draft: JLG, DVF, CRC; writing—review: all authors.

Funding This work was financially supported by the São Paulo Research Foundation-FAPESP (grant 2018/15294-3) and National Council for Scientific and Technological Development-CNPq (grant 167750/2018-6).

\section{Declarations}

Conflict of interest The authors declare no conflict of interest.

Open Access This article is licensed under a Creative Commons Attribution 4.0 International License, which permits use, sharing, adaptation, distribution and reproduction in any medium or format, as long as you give appropriate credit to the original author(s) and the source, provide a link to the Creative Commons licence, and indicate if changes were made. The images or other third party material in this article are included in the article's Creative Commons licence, unless indicated otherwise in a credit line to the material. If material is not included in the article's Creative Commons licence and your intended use is not permitted by statutory regulation or exceeds the permitted use, you will need to obtain permission directly from the copyright holder. To view a copy of this licence, visit http://creativecommons.org/licenses/by/4.0/.

\section{References}

1. Apovian CM (2016) Obesity: definition, comorbidities, causes, and burden. Am J Manag Care 22:176-185. http://www.ncbi.nlm. nih.gov/pubmed/27356115. Accessed 25 Feb 2020

2. Albuquerque D, Nóbrega C, Manco L, Padez C (2017) The contribution of genetics and environment to obesity. Br Med Bull 123(1):159-173. https://academic.oup.com/bmb/article/123/1/ $159 / 3930933$

3. World Health Organization (2020) Fact sheets: obesity and overweight. https://www.who.int/news-room/fact-sheets/detail/obesi ty-and-overweight. Accessed 20 Aug 2020

4. Ebong IA, Goff DC, Rodriguez CJ, Chen H, Bertoni AG (2014) Mechanisms of heart failure in obesity. Obes Res Clin Pract 8(6):540-548. https://linkinghub.elsevier.com/retrieve/pii/ S1871403X1300224X. Accessed 12 Apr 2020

5. Alpert M, Omran J, Bostick B (2016) Effects of obesity on cardiovascular hemodynamics, cardiac morphology, and ventricular function. Curr Obes Rep 5:424-434. https://link.springer. com/article/10.1007\%2Fs13679-016-0235-6. Accessed 12 Apr 2020 
6. Vecchié A, Dallegri F, Carbone F, Bonaventura A, Liberale L, Portincasa P, et al (2018) Obesity phenotypes and their paradoxical association with cardiovascular diseases. Eur J Intern Med 48:6-17. https://linkinghub.elsevier.com/retrieve/pii/ S0953620517304284. Accessed 12 Apr 2020

7. Fuster JJ, Ouchi N, Gokce N, Walsh K (2016) Obesity-induced changes in adipose tissue microenvironment and their impact on cardiovascular disease. Circ Res 118(11):1786-1807. https:// doi.org/10.1161/CIRCRESAHA.115.306885

8. Bhatheja S, Panchal HB, Ventura H, Paul TK (2016) Obesity cardiomyopathy: pathophysiologic factors and nosologic reevaluation. Am J Med Sci 352(2):219-222. http://www.ncbi.nlm. nih.gov/pubmed/27524223. Accessed 29 Apr 2020

9. González S (2020) Dietary bioactive compounds and human health and disease. Nutrients 12(2):348. https://doi.org/10.3390/ nu12020348

10. Sharifi-Rad J, Rodrigues CF, Sharopov F et al (2020) Diet, lifestyle and cardiovascular diseases: linking pathophysiology to cardioprotective effects of natural bioactive compounds. Int J Environ Res Pub Health 17(7):2326. https://doi.org/10.3390/ijerph1707 2326

11. Sharif MK, Butt MS, Anjum FM, Khan SH (2014) Rice bran: a novel functional ingredient. Crit Rev Food Sci Nutr 54(6):807816. https://doi.org/10.1080/10408398.2011.608586

12. Van Nguyen N, Ferrero A (2006) Meeting the challenges of global rice production. Paddy Water Environ 4(1):1-9. https://doi.org/10. 1007/s10333-005-0031-5

13. Minatel IO, Francisqueti FV, Corrêa CR, Pereira Lima GP (2016) Antioxidant activity of Y-oryzanol: a complex network of interactions. Int J Mol Sci 17(8):1107. https://doi.org/10.3390/ijms1 7081107

14. Sohail M, Rakha A, Butt MS, Iqbal MJ, Rashid S (2017) Rice bran nutraceutics: a comprehensive review. Crit Rev Food Sci Nutr 57(17):3771-3780. http://www.ncbi.nlm.nih.gov/pubmed/ 27015585. Accessed 29 Nov 2019

15. Bergman CJ, Xu Z (2003) Genotype and environment effects on tocopherol, tocotrienol, and $\gamma$-oryzanol contents of southern U.S. rice. Cereal Chem J 80(4):446-449. https://doi.org/10.1094/ CCHEM.2003.80.4.446

16. Yang S, Huang W, Ng X, Lee M, Hsu Y, Huang C et al (2019) Rice bran reduces weight gain and modulates lipid metabolism in rats with high-energy-diet-induced obesity. Nutrients 11(9):2033. https://doi.org/10.3390/nu11092033

17. Ha TY, Han S, Kim SR, Kim IH, Lee HY, Kim HK (2005) Bioactive components in rice bran oil improve lipid profiles in rats fed a high-cholesterol diet. Nutr Res 25(6):597-606. https://doi.org/ 10.1016/j.nutres.2005.05.003

18. Zou Y, Ju X, Chen W, Yuan J, Wang Z, Aluko RE, et al. (2020) Rice bran attenuated obesity via alleviating dyslipidemia, browning of white adipocytes and modulating gut microbiota in highfat diet-induced obese mice. Food Funct 11(3):2406-2417. http:// xlink.rsc.org/?DOI=C9FO01524H. Accessed 15 May 2020

19. Rao YPC, Sugasini D, Lokesh BR (2016) Dietary gamma oryzanol plays a significant role in the anti-inflammatory activity of rice bran oil by decreasing pro-inflammatory mediators secreted by peritoneal macrophages of rats. Biochem Biophys Res Commun 479(4):747-752. http://www.ncbi.nlm.nih.gov/pubmed/ 27693794. Accessed 13 May 2020

20. Kilkenny C, Browne WJ, Cuthill IC, Emerson M, Altman DG (2010) Improving bioscience research reporting: the ARRIVE guidelines for reporting animal research. PLoS Biol 8(6):e1000412. https://doi.org/10.1371/journal.pbio.1000412

21. Francisqueti FV, Minatel IO, Ferron AJT, Bazan SGZ, Silva VD, Garcia JL, et al. (2017) Effect of gamma-oryzanol as therapeutic agent to prevent cardiorenal metabolic syndrome in animals submitted to high sugar-fat diet. Nutrients 9(12):1299. http://www. mdpi.com/2072-6643/9/12/1299. Accessed 28 Feb 2020

22. Costa MR, Garcia JL, Silva CCVA, Ferron ATJ, FrancisquetiFerron FV, Hasimoto FK et al (2019) Lycopene modulates pathophysiological processes of non-alcoholic fatty liver disease in obese rats. Antioxidants 8(8):276. https://doi.org/10.3390/antio x 8080276

23. Ferron AJT, Aldini G, Francisqueti-ferron FV, Silva CCVA, Bazan SZG, Garcia JL et al (2019) Protective effect of tomato-oleoresin supplementation on oxidative injury recoveries cardiac function by improving $\beta$-adrenergic response in a diet-obesity induced model. Antioxidants 8(9):368. https://doi.org/10.3390/antiox8090 368

24. Sheflin AM, Borresen EC, Wdowik MJ, Rao S, Brown RJ, Heuberger AL et al (2015) Pilot dietary intervention with heatstabilized rice bran modulates stool microbiota and metabolites in healthy adults. Nutrients 7(2):1282-1300. https://doi.org/10. 3390/nu7021282

25. Kahlon TS, Chow FI, Sayre RY, Betschart AA (1992) Cholesterol-lowering in hamsters fed rice bran at various levels, defatted rice bran and rice bran oil. J Nutr 122(3):513-519. https:// doi.org/10.1093/jn/122.3.513

26. Tran M, Forget P, Van den Neucker A, Strik J, van Kreel B, Kuijten R (1994) The acid steatocrit: a much improved method. J Pediatr Gastroenterol Nutr 19(3):299-303. https://doi.org/10. 1097/00005176-199410000-00007

27. Meitern R, Lind M-A, Karu U, Hõrak P (2016) Simple and noninvasive method for assessment of digestive efficiency: validation of fecal steatocrit in greenfinch coccidiosis model. Ecol Evol 6(24):8756-8763

28. Dos SPP, Rafacho BPM, Gonçalves ADF, Jaldin RG, Do NTB, Silva MAB et al (2014) Vitamin D Induces increased systolic arterial pressure via vascular reactivity and mechanical properties. PLoS ONE 9(6):e98895. https://doi.org/10.1371/journal. pone.0098895

29. Vileigas DF, Marciano CLC, Mota GAF, Souza SLB, Sant'Ana PG, Okoshi K et al (2020) Temporal measures in cardiac structure and function during the development of obesity induced by different types of western diet in a rat model. Nutrients 12(1):115. https://doi.org/10.3390/nu12010068

30. Marklund SL (1985) Product of extracellular-superoxide dismutase catalysis. FEBS Lett 184(2):237-239. https://doi.org/ 10.1016/0014-5793(85)80613-X

31. Aebi H (1974) Catalase. Methods Enzym Anal 2:673-684. https://doi.org/10.1016/B978-0-12-091302-2.50032-3

32. Flohé L, Günzler WA (1984) Assays of glutathione peroxidase. Methods Enzymol 105:114-120. https://doi.org/10.1016/s00766879(84)05015-1

33. Mesquita CS, Oliveira R, Bento F, Geraldo D, Rodrigues JV, Marcos JC (2014) Simplified 2,4-dinitrophenylhydrazine spectrophotometric assay for quantification of carbonyls in oxidized proteins. Anal Biochem 458:69-71. https://doi.org/10.1016/j.ab. 2014.04.034

34. Samarghandian S, Farkhondeh T, Samini F, Borji A (2016) Protective effects of carvacrol against oxidative stress induced by chronic stress in rat's brain, liver and kidney. Biochem Res Int 2016:2645237. https://doi.org/10.1155/2016/2645237

35. Metsalu T, Vilo J (2015) ClustVis: a web tool for visualizing clustering of multivariate data using principal component analysis and heatmap. Nucleic Acids Res 43(W1):W566-W570. https://doi.org/10.1093/nar/gkv468

36. World Health Organization (2017) Fact sheets: cardiovascular diseases (CVDs), https://www.who.int/news-room/fact-sheets/ detail/cardiovascular-diseases-(cvds). Accessed 23 Nov 2020

37. Yoon G-A, Yeum K, Cho Y, Chen CO, Tang G, Blumberg JB et al (2012) Carotenoids and total phenolic contents in plant 
foods commonly consumed in Korea. Nutr Res Pract 6(6):481490. https://doi.org/10.4162/nrp.2012.6.6.481

38. Longo M, Zatterale F, Naderi J, Parrillo L, Formisano P, Raciti GA, et al. (2019) Adipose tissue dysfunction as determinant of obesity-associated metabolic complications. Int J Mol Sci 20(9):2358. http://www.ncbi.nlm.nih.gov/pubmed/31085992. Accessed 2 July 2020

39. Pellegrinelli V, Carobbio S, Vidal-Puig A (2016) Adipose tissue plasticity: how fat depots respond differently to pathophysiological cues. Diabetologia 59(6):1075-1088. http://www.ncbi. nlm.nih.gov/pubmed/27039901. Accessed 2 July 2020

40. Manna P, Jain SK (2015) Obesity, oxidative stress, adipose tissue dysfunction, and the associated health risks: causes and therapeutic strategies. Metab Syndr Relat Disord 13(10):423444. http://www.ncbi.nlm.nih.gov/pubmed/26569333. Accessed 4 June 2020

41. Jin Son M, W. Rico C, Hyun Nam S, Young Kang M (2010) Influence of oryzanol and ferulic acid on the lipid metabolism and antioxidative status in high fat-fed mice. J Clin Biochem Nutr 46(2):150-156. http://joi.jlc.jst.go.jp/JST.JSTAGE/jcbn/09-98? from $=$ CrossRef. Accessed 27 June 2020

42. Ham H, Sung J, Lee J (2015) Effect of rice bran unsaponifiables on high-fat diet-induced obesity in mice. J Food Biochem. https:// doi.org/10.1111/jfbc. 12170

43. Justo ML, Claro C, Zeyda M, Stulnig TM, Herrera MD, Rodríguez-Rodríguez R (2019) Rice bran prevents high-fat dietinduced inflammation and macrophage content in adipose tissue. Eur J Nutr 55(6):2011-2019. https://doi.org/10.1007/ s00394-015-1015-x

44. Boonloh K, Kukongviriyapan V, Kongyingyoes B, Kukongviriyapan U, Thawornchinsombut S, Pannangpetch P (2015) Rice bran protein hydrolysates improve insulin resistance and decrease proinflammatory cytokine gene expression in rats fed a high carbohydrate-high fat diet. Nutrients 7(8):6313-6329. https://doi.org/ 10.3390/nu7085292

45. Holland WL, Bikman BT, Wang L-P, Yuguang G, Sargent KM, Bulchand S, et al. (2011) Lipid-induced insulin resistance mediated by the proinflammatory receptor TLR4 requires saturated fatty acid-induced ceramide biosynthesis in mice. J Clin Invest 121(5):1858-1870. http://www.jci.org/articles/view/43378. Accessed 13 Sept 2020

46. Lê K-A, Mahurkar S, Alderete TL, Hasson RE, Adam TC, Kim JS et al (2011) Subcutaneous adipose tissue macrophage infiltration is associated with hepatic and visceral fat deposition, hyperinsulinemia, and stimulation of NF- $\mathrm{BB}$ stress pathway. Diabetes 60(11):2802-2809. https://doi.org/10.2337/db10-1263

47. Abel ED, Litwin SE, Sweeney G (2008) Cardiac remodeling in obesity. Physiol Rev 88(2):389-419. http://www.ncbi.nlm.nih. gov/pubmed/18391168. Accessed 16 Oct 2020

48. Tune JD, Goodwill AG, Sassoon DJ, Mather KJ (2017) Cardiovascular consequences of metabolic syndrome. Transl Res 183:5770. http://www.ncbi.nlm.nih.gov/pubmed/28130064. Accessed 28 Oct 2020

49. Alpert MA, Karthikeyan K, Abdullah O, Ghadban R (2018) Obesity and cardiac remodeling in adults: mechanisms and clinical implications. Prog Cardiovasc Dis 61(2):114-123. http://www. ncbi.nlm.nih.gov/pubmed/29990533. Accessed 28 Oct 2020

50. Vileigas DF, Cicogna AC (2021) Effects of obesity on the cardiac proteome. Endocrine Metab Sci 2:100076. https://doi.org/ 10.1016/j.endmts.2020.100076
51. Ge C-X, Xu M-X, Qin Y-T, Gu T-T, Lou D-S, Li Q, et al (2019) Endoplasmic reticulum stress-induced iRhom2 up-regulation promotes macrophage-regulated cardiac inflammation and lipid deposition in high fat diet (HFD)-challenged mice: intervention of fisetin and metformin. Free Radic Biol Med 141:67-83. http:// www.ncbi.nlm.nih.gov/pubmed/31153974. Accessed 28 Oct 2020

52. Duansak N, Piyabhan P, Srisawat U, Naowaboot J, Lerdvuthisopon N, Schmid-Schönbein G (2020) The effect of rice bran extract on arterial blood pressure, hepatic steatosis, and inflammation in mice fed with a high-fat diet. J Nutr Metab 2020:8374287. https:// www.hindawi.com/journals/jnme/2020/8374287/. Accessed 23 Oct 2020

53. Islam MS, Murata T, Fujisawa M, Nagasaka R, Ushio H, Bari AM, et al (2008) Anti-inflammatory effects of phytosteryl ferulates in colitis induced by dextran sulphate sodium in mice. Br J Pharmacol 154(4):812-824. http://www.ncbi.nlm.nih.gov/pubmed/18536 734. Accessed 6 Oct 2020

54. Xiao J, Zhang R, Wu Y, Wu C, Jia X, Dong L, et al. (2020) Rice bran phenolic extract protects against alcoholic liver injury in mice by alleviating intestinal microbiota dysbiosis, barrier dysfunction, and liver inflammation mediated by the endotoxin-TLR4-NF- $\mathrm{BB}$ pathway. J Agric Food Chem 68(5):1237-1247. http://www.ncbi. nlm.nih.gov/pubmed/31722525. Accessed 7 Oct 2020

55. Rodrigo R, Libuy M, Feliú F, Hasson D (2013) Oxidative stressrelated biomarkers in essential hypertension and ischemia-reperfusion myocardial damage. Dis Markers 35(6):773-790. http:// www.ncbi.nlm.nih.gov/pubmed/24347798. Accessed 7 Oct 2020

56. Panchal SS, Patidar RK, Jha AB, Allam AA, Ajarem J, Butani SB (2017) Anti-inflammatory and antioxidative stress effects of oryzanol in glaucomatous rabbits. J Ophthalmol 2017:1-9. https:// www.hindawi.com/journals/joph/2017/1468716/. Accessed 8 Sept 2020

57. Tan XW, Bhave M, Fong AYY, Matsuura E, Kobayashi K, Shen LH, et al (2016) Cytoprotective and cytotoxic effects of rice bran extracts in rat H9c2(2-1) cardiomyocytes. Oxid Med Cell Longev 2016:1-12. http://www.hindawi.com/journals/omcl/2016/69430 53/. Accessed 30 Nov 2020

58. Rungratanawanich W, Memo M, Uberti D (2018) Redox homeostasis and natural dietary compounds: focusing on antioxidants of rice (Oryza sativa L.). Nutrients 10(11). http://www.ncbi.nlm.nih. gov/pubmed/30388764. Accessed 1 Dec 2020

59. Srinivasan M, Sudheer AR, Menon VP (2007) Ferulic acid: therapeutic potential through its antioxidant property. J Clin Biochem Nutr 40(2):92-100. https://www.jstage.jst.go.jp/article/jcbn/40/2/ 40_2_92/_article. Accessed 30 Nov 2020

60. Nair A, Jacob S (2016) A simple practice guide for dose conversion between animals and human. J Basic Clin Pharm 7(2):27. https://doi.org/10.4103/0976-0105.177703

61. Reagan-Shaw S, Nihal M, Ahmad N (2008) Dose translation from animal to human studies revisited. FASEB J 22(3):659-661. https://doi.org/10.1096/fj.07-9574LSF

62. Zhu M-J, Kang Y, Xue Y, Liang X, García MPG, Rodgers D et al (2018) Red raspberries suppress NLRP3 inflammasome and attenuate metabolic abnormalities in diet-induced obese mice. J Nutr Biochem 53:96-103. https://doi.org/10.1016/j.jnutbio.2017. 10.012 